\title{
Early fortification of enteral feedings for infants $<1250$ grams birth weight receiving a human milk diet including human milk based fortifier
}

\author{
Robert Huston ${ }^{\mathrm{a}, *}$, Martin Lee ${ }^{\mathrm{b}}$, Evelyn Rider ${ }^{\mathrm{c}}$, Melissa Stawarz ${ }^{\mathrm{d}}$, Dawn Hedstrom ${ }^{\mathrm{e}}$, \\ Melissa Pence $^{\mathrm{f}}$, Vera Chan ${ }^{\mathrm{b}}$, Jessica Chambers ${ }^{\mathrm{c}}$, Stefanie Rogers ${ }^{\mathrm{d}}$, Nadine Sager ${ }^{\mathrm{e}}$, \\ Laurie Riemann ${ }^{\mathrm{e}}$ and Howard Cohen ${ }^{\mathrm{f}}$ \\ ${ }^{\mathrm{a} N o r t h w e s t ~ N e w b o r n ~ S p e c i a l i s t s, ~ P C ~ a n d ~ P e d i a t r i x ~ M e d i c a l ~ G r o u p, ~ P o r t l a n d, ~ O R, ~ U S A ~}$ \\ ${ }^{\mathrm{b}}$ Prolacta Bioscience, Duarte, CA, USA \\ ${ }^{\mathrm{c}}$ Providence Alaska Medical Center, Anchorage, AK, USA \\ ${ }^{\mathrm{d}}$ Providence St. Vincent Medical Center, Portland, OR, USA \\ ${ }^{\mathrm{e}}$ Billings Clinic, Billings, MT, USA \\ ${ }^{\mathrm{f}}$ Salem Health Hospitals and Clinics, Salem, OR, USA
}

Received 17 June 2019

Revised 13 August 2019

Accepted 6 October 2019

\begin{abstract}
.
BACKGROUND: An exclusive human milk diet (EHM) including fortification with a human milk-based fortifier has been shown to decrease the occurrence of necrotizing enterocolitis (NEC) but growth velocity may be less for infants receiving EHM compared to a bovine diet.

OBJECTIVE: The objective of this study was to determine if growth is improved by earlier fortification of breast milk for preterm infants supported with a human milk based fortifier.

STUDY DESIGN: A multi-center retrospective cohort study of the outcomes of infants of 500-1250 g birth weight whose breast milk feedings were fortified at $>60 \mathrm{~mL} / \mathrm{kg} /$ day (late) versus $<60 \mathrm{~mL} / \mathrm{kg} /$ day (early) of enteral feeding volume.

RESULTS: Median \pm IQR range for gestational age (27.6 \pm 3.4 vs $27.0 \pm 2.9$ weeks, $p=0.03)$ and chronic lung disease (CLD: 42.6 vs $27.6 \%, p=0.008)$ were higher, and weight gain ( $12.9 \pm 2.6$ vs $13.3 \pm 2.6 \mathrm{~g} / \mathrm{kg} / \mathrm{day}, p=0.03)$ was lower in the late $(\mathrm{N}=102)$ vs the early $(\mathrm{N}=292)$ group. Adjusted multiple linear regression analysis found that early fortification was associated with improved growth velocity for weight $(p=0.007)$ and head circumference $(\mathrm{HC})(p=0.021)$ and less negative changes in z-scores for weight $(p=0.022)$ and $\mathrm{HC}(p=0.046)$ from birth to discharge. Adjusted multiple logistic regression found that early fortification was associated with decreased occurrence of CLD $(p=0.004)$. No other outcomes, including NEC, were associated with early versus late fortification.
\end{abstract}


CONCLUSION: The study results suggested that early HM fortification appears to positively affect growth for infants whose human milk feedings are fortified with a human milk based fortifier without adverse effects. The incidence of CLD was also reduced in the early fortification group.

Keywords: Human milk, fortification, growth, clinical outcomes

\section{Introduction}

An exclusive human milk (EHM) diet composed of mother's own breast milk supplemented with banked donor human milk when breast milk is not available and a human milk-based human milk fortifier has been shown to reduce the incidence of necrotizing enterocolitis (NEC), a significant cause of morbidity and mortality in preterm infants, compared to a bovine diet composed of preterm formula either exclusively or as a supplement to breast milk [1-3]. In the bovine diet breast milk was also supplemented with a bovine-based fortifier. However, in some studies that reported growth, there has been decreased weight gain in infants supported with the EHM diet compared to a bovine diet $[2,4]$. Growth for infants receiving the EHM diet has been improved by fortifying breast milk earlier than the previous practice of fortifying at $100 \mathrm{~mL} / \mathrm{kg} /$ day of enteral feeding volume [4-5] and by adding additional calories in the form of human milk cream when fortifying at less than or equal to $100 \mathrm{~mL} / \mathrm{kg} /$ day [6]. Other studies have not found an improvement in growth parameters associated with earlier fortification of human milk feedings using a human milk based fortifier [1] or a bovine fortifier [7-8]. Since results have been variable in these studies there is a need for more studies to determine if an earlier fortification strategy improves growth for preterm infants $<1250 \mathrm{~g}$ birth weight who are supported with an EHM diet. Therefore, the objective of this study was to determine if growth is improved by earlier fortification of breast milk for infants in this population. Clinical outcomes were also evaluated.

\section{Methods}

This study was a multi-center retrospective cohort study of the outcomes of infants of 500-1250 g birth weight whose breast milk feedings were fortified with a human milk-based fortifier at $>60 \mathrm{~mL} / \mathrm{kg} /$ day (late) versus those whose feedings were fortified at $<60 \mathrm{~mL} / \mathrm{kg} /$ day (early) of enteral feeding volume. Infants who were admitted to the neonatal intensive care unit (NICU) from August, 2013 to December,
2017 at four study sites on or before day of life 3 who remained in the NICU until they began receiving fortified breast milk and who received an EHM diet qualified for the study. The study was approved by the institutional review boards of all centers. Infants with gastrointestinal, complex cardiac, or other major anomalies, those who developed NEC or intestinal perforation prior to milk fortification, and those with genetic or metabolic syndromes were excluded. Initial fortification was with human milk based fortifier (Prolacta Bioscience Inc., City of Industry, CA) at $24-26 \mathrm{Kcal} / \mathrm{oz}$. Fortification with the human milk based fortifier was continued for at least 3 weeks or until 34-35 weeks postmenstrual age (PMA). Mother's own breast milk was supplemented with banked donor breast milk as needed until 34-35 weeks PMA. Infants who were fortified at volumes $<60 \mathrm{~mL} / \mathrm{kg} /$ day were further fortified with human milk based fortifier to $26 \mathrm{Kcal} / \mathrm{oz}$ at enteral feeding volumes of $80-100 \mathrm{~mL} / \mathrm{kg} / \mathrm{day}$ while those who were initially fortified at $>60 \mathrm{~mL} / \mathrm{kg} /$ day were further fortified when receiving enteral intakes of $120-130 \mathrm{~mL} / \mathrm{kg} / \mathrm{day}$. Infants who were fluid restricted or exhibited poor growth were further fortified to $28 \mathrm{Kcal} / \mathrm{oz}$ with human milk based fortifier. When human milk based fortifier was discontinued a liquid bovine fortifier was begun (Similac Human Milk Fortifier Concentrated Liquid, Abbott Laboratories, Columbus, $\mathrm{OH}$, or Enfamil Human Milk Fortifier Acidified Liquid, Mead Johnson \& Co. Evansville, IN). Guidelines for parenteral nutrition (PN) support included initiating amino acid intake of $0.5-3 \mathrm{~g} / \mathrm{kg} /$ day on day of life 1 and lipid emulsion infusion of $1-2 \mathrm{~g} / \mathrm{kg} / \mathrm{day}$ on day of life $1-2$. Amino acid and lipid intakes were increased by $0.5-1 \mathrm{~g} / \mathrm{kg} / \mathrm{day}$ to goals of $3.5-4 \mathrm{~g} / \mathrm{kg} / \mathrm{day}$ of AA and $3 \mathrm{~g} / \mathrm{kg} /$ day of lipid emulsion.

Data collection included birth and discharge weight and head circumference. Gestational age at birth, sex, Apgar at 5 minutes, maternal treatment with prenatal steroids, weight for gestational age at birth <10th percentile (SGA) on the Fenton 2013 growth curve [9], total days of mechanical ventilation, and treatment with postnatal corticosteroids were recorded. Total days receiving PN and day 
of life of first enteral feeding were recorded. Clinical data included the occurrence of patent ductus arteriosus, NEC (defined as modified Bell stage 2 or stage 3) [10], any late infection (a late bacterial infection and/or coagulase negative staphylococcal and/or fungal Infection occurring in a blood or cerebrospinal fluid culture after day 3 of life), chronic lung disease (defined as requiring supplemental oxygen at a PMA of 36 weeks or receiving supplemental oxygen if discharged between 34 and 36 weeks), severe retinopathy of prematurity (stage 3 or greater or requiring surgery), severe intraventricular hemorrhage (grade 3 or 4), and mortality.

Primary outcomes included weight and occipitalfrontal head circumference gain velocities and changes in weight and head circumference z-scores from birth to discharge. Weight gain velocity was calculated using the exponential method [11]. Head circumference was measured using a non-flexible tape measure. Z-scores and change in z-scores from birth to discharge were calculated for weight and head circumference using the Fenton 2013 growth curve data. Secondary outcomes included the occurrence of NEC, any late infection, chronic lung disease (CLD), severe retinopathy of prematurity, and mortality.

All data were summarized using appropriate descriptive statistics: either mean \pm standard deviation or median \pm interquartile range for quantitative data or counts/proportions/percentages for qualitative (categorical) data. Baseline information comparing the early and late fortification groups was analyzed using either the Wilcoxon rank-sum test or the oneway analysis of variance (and sub-analyzed where necessary using the Tukey HSD method) for quantitative outcomes, or the chi-square/Fisher's exact test for categorical results. To perform an unadjusted analysis of any difference between the study groups for these various parameters, the Wilcoxon rank-sum test was used. Since the study groups were not randomly assigned, group differences were also evaluated using a multivariate adjustment model based on a multiple linear regression model with the outcome transformed using the Box-Cox power or Yeo-Johnson transformations due to a lack of normality in these data. The adjustment variables considered were birth weight/head circumference, gestational age (GA), gender, SGA status, CLD, PN days, and study site. For qualitative outcomes such as CLD, NEC and other secondary outcomes, the unadjusted analyses used the chi-square test for homogeneity and the adjustment of the results used the multiple logistic regression model with similar covariates as noted above. For CLD, covariates used were significant patent ductus arteriosus, late infection, days of mechanical ventilation, NEC, and prenatal steroids in addition to fortification, birth weight, GA, SGA, sex, and site. All analyses used a 5\% significance level and were two-sided in nature. Statistical analyses were performed using R (R Core Team (2017). R: A language and environment for statistical computing. $R$ Foundation for Statistical Computing, Vienna, Austria. URL https://www.R-project.org/ and StatXact1 1 (Cytel Software, Inc., Cambridge, MA, 2015).

\section{Results}

A total of 394 infants qualified for the study. The total infants included from each of the 4 study sites were: Site 1, 32/169; Site 2, 32/99; Site 3, 34/1; Site 4, 4/23 (late/early). Table 1 lists the baseline characteristics for the two fortification groups. The gestational age and head circumference at birth were lower in the early versus the late group. Table 2 lists the clinical outcomes and shows that the incidence of chronic lung disease was lower in the early versus the late group. Table 3 lists nutritional outcomes. Day of life of fortification to $24 \mathrm{Kcal} / \mathrm{oz}$ was earlier and volume of enteral feeding at the time of fortification was lower in the early group. Weight gain velocity was greater in the early group.

The results of the linear regression analyses for growth velocities and changes in z-scores from birth to discharge for weight and head circumference are shown in Tables 4 and 5, respectively. Early fortification was associated with improved growth velocities and less negative changes in z-scores for both anthropometric outcomes. Birth measurements and gestational age at birth were important predictors for these growth parameters. There were associations related to study site. For these analyses data for sites 3 and 4 were combined because almost all infants from these sites were in either the early or late fortification group.

Multiple logistic regression analysis for CLD showed a significant negative association with early fortification (coefficient, standard error, $p$-value: $-0.965,0.331, p=0.004)$. There were positive associations with site $2(2.067,0.347, p<0.001)$, sites 3-4 $(1.110,0.469, p=0.018)$, patent ductus arteriosus $(1.294,0.297, p<0.001)$, and days of mechanical ventilation $(0.036,0.011, p=0.002)$. There were no associations of fortification group with any other clinical outcome, including NEC. 
Table 1

Baseline characteristics (median $\pm \mathrm{IQR}$ or number [\%])

\begin{tabular}{|c|c|c|c|c|c|}
\hline Characteristic & Late $\mathrm{N}$ & Late & Early N & Early & $p$-Value \\
\hline GA & 102 & $27.6 \pm 3.4$ & 292 & $27.0 \pm 2.9$ & 0.03 \\
\hline BW & 102 & $972 \pm 340$ & 292 & $920 \pm 352$ & 0.08 \\
\hline BW z-score & 102 & $-0.16 \pm 1.46$ & 292 & $-0.04 \pm 1.34$ & 0.22 \\
\hline $\mathrm{BHC}$ & 100 & $25.0 \pm 3.0$ & 292 & $24.5 \pm 3.5$ & 0.02 \\
\hline BHC z-score & 100 & $-0.11 \pm 1.45$ & 292 & $-0.15 \pm 1.39$ & 0.79 \\
\hline SGA & 102 & $20(19.6 \%)$ & 292 & $38(13.0 \%)$ & 0.14 \\
\hline Male Sex & 102 & $53(52.0 \%)$ & 292 & $130(44.5 \%)$ & 0.24 \\
\hline Inborn & 102 & $98(96.1 \%)$ & 292 & $278(95.2 \%)$ & 0.83 \\
\hline Apgar 5 & 102 & $8 \pm 2$ & 292 & $7 \pm 2$ & 0.12 \\
\hline PNS & 102 & $93(91.2 \%)$ & 292 & $273(93.5 \%)$ & 0.57 \\
\hline Non Hisp White & 102 & $58(56.9 \%)$ & 292 & $149(51.0 \%)$ & 0.90 \\
\hline Non Hisp Black & 102 & $9(8.8 \%)$ & 292 & $37(12.7 \%)$ & 0.90 \\
\hline Hisp & 102 & $6(5.9 \%)$ & 292 & $20(6.8 \%)$ & 0.90 \\
\hline Asian & 102 & $10(9.8 \%)$ & 292 & $29(9.9 \%)$ & 0.90 \\
\hline Other & 102 & $17(16.7 \%)$ & 292 & $51(17.5 \%)$ & 0.90 \\
\hline
\end{tabular}

Apgar 5, Apgar score at 5 minutes; BHC, birth head circumference; BW, birth weight; GA, gestational age at birth; Hisp, Hispanic race; IQR, interquartile range; PNS, prenatal steroids; SGA, small for gestational age.

Table 2

Clinical outcomes (median $\pm \mathrm{IQR}$ or number [\%])

\begin{tabular}{lccccc}
\hline Characteristic & Late N & Late & Early N & Early & $p$-Value \\
\hline CLD & 101 & $43(42.6 \%)$ & 286 & $79(27.6 \%)$ & 0.008 \\
MV (days) & 102 & $1 \pm 5.75$ & 292 & $0 \pm 6.50$ & 0.72 \\
PostNS & 102 & $15(14.7 \%)$ & 292 & $28(9.6 \%)$ & 0.21 \\
All PDA & 102 & $43(42.2 \%)$ & 292 & $127(43.5 \%)$ & 0.91 \\
SPDA Ligation & 102 & $3(2.9 \%)$ & 292 & $15(5.1 \%)$ & 0.52 \\
NEC & 102 & $4(3.9 \%)$ & 292 & $15(5.1 \%)$ & 0.64 \\
Surgical NEC & 102 & $1(1.0 \%)$ & 292 & $8(2.7 \%)$ & 0.35 \\
Late Infection & 102 & $12(11.8 \%)$ & 292 & $30(10.3 \%)$ & 0.82 \\
SROP & 102 & $13(12.7 \%)$ & 285 & $48(16.8 \%)$ & 0.39 \\
SIVH & 102 & $4(3.9 \%)$ & 291 & $12(4.1 \%)$ & 1 \\
Mortality & 102 & $5(4.9 \%)$ & 292 & $14(4.8 \%)$ & 1 \\
Stay (days) & 102 & $79.5 \pm 31.8$ & 291 & $79.0 \pm 36.0$ & 0.61 \\
\hline
\end{tabular}

CLD, chronic lung disease; IQR, interquartile range; MV, mechanical ventilation; NEC, necrotizing enterocolitis; PDA, patent ductus arteriosus; SPDA, patent ductus arteriosus closed surgically; PostNS, postnatal steroids; SIVH, severe intracranial hemorrhage; SROP, severe retinopathy of prematurity.

Table 3

Nutritional outcomes (median \pm IQR or number [\%])

\begin{tabular}{|c|c|c|c|c|c|}
\hline Characteristic & Late $\mathrm{N}$ & Late & Early N & Early & $p$-Value \\
\hline DOL EF & 102 & $2 \pm 1$ & 292 & $2 \pm 0$ & $<0.001$ \\
\hline PN (days) & 102 & $14.0 \pm 9.0$ & 291 & $12.0 \pm 10.0$ & 0.73 \\
\hline DOL $24 \mathrm{Kcal} / \mathrm{oz}$ & 102 & $12 \pm 7$ & 292 & $8 \pm 5$ & $<0.001$ \\
\hline Vol $24 \mathrm{Kcal} / \mathrm{oz}(\mathrm{mL} / \mathrm{kg} /$ day $)$ & 102 & $96.0 \pm 32.8$ & 292 & $50.0 \pm 38.3$ & $<0.001$ \\
\hline $\mathrm{DC}$ Wt $(\mathrm{g})$ & 101 & $2694 \pm 994$ & 291 & $2685 \pm 903$ & 0.65 \\
\hline DC Wt z-score & 101 & $-1.480 \pm 1.480$ & 291 & $-1.290 \pm 1.370$ & 0.10 \\
\hline Change in Wt z-score & 101 & $-1.29 \pm 1.00$ & 291 & $-1.22 \pm 0.91$ & 0.37 \\
\hline $\mathrm{DC}$ OFC $(\mathrm{cm})$ & 101 & $33 \pm 3$ & 291 & $33 \pm 3$ & 0.88 \\
\hline DC OFC z-score & 101 & $-1.050 \pm 1.190$ & 291 & $-0.920 \pm 1.368$ & 0.67 \\
\hline Change in OFC z-score & 97 & $-0.820 \pm 1.350$ & 291 & $-0.735 \pm 1.375$ & 0.83 \\
\hline Wt GV (g/kg/day) & 101 & $12.9 \pm 2.6$ & 291 & $13.3 \pm 2.6$ & 0.03 \\
\hline OFC GV (cm/week) & 97 & $0.73 \pm 0.17$ & 291 & $0.74 \pm 0.16$ & 0.36 \\
\hline
\end{tabular}

DC, discharge; DOL, day of life; EF, enteral feeding; GV, growth velocity; IQR, interquartile range; OFC, occipital frontal head circumference; PN, parenteral nutrition; Vol, volume; Wt, weight. 
Table 4

Models for linear regression analyses for weight

\begin{tabular}{llcccccc}
\hline Parameter & Independent & Coefficient & SE & $\begin{array}{c}t \\
\text { Statistic }\end{array}$ & $p$-Value & $\begin{array}{c}\text { Adjusted } \\
\mathrm{R}^{2}\end{array}$ & $\begin{array}{c}\text { Feature } \\
\text { importance }\end{array}$ \\
\hline Weight Velocity $^{1}$ & Early FF & 1.636 & 0.508 & 2.734 & 0.007 & 0.288 & $3.8 \%$ \\
& Birth weight & -0.011 & 0.002 & -7.638 & $<0.001$ & & $22.3 \%$ \\
& Gestational age & 0.996 & 0.154 & 5.315 & $<0.001$ & $12.6 \%$ \\
& SGA & -1.440 & 0.798 & -1.591 & 0.112 & $6.4 \%$ \\
& Sex & 0.775 & 0.420 & 1.710 & 0.088 & $1.1 \%$ \\
& CLD & -0.445 & 0.522 & -0.854 & 0.394 & $1.3 \%$ \\
& PN days & -0.069 & 0.010 & -6.625 & $<0.001$ & $31.2 \%$ \\
Weight Change in & Site 2 & 2.721 & 0.492 & 5.528 & $<0.001$ & & $18.6 \%$ \\
z-score & Site 3-4 & 1.783 & 0.656 & 2.719 & 0.007 & & $2.6 \%$ \\
& Early FF & 0.238 & 0.103 & 2.300 & 0.022 & 0.134 & $4.9 \%$ \\
& Birth weight & -0.001 & 0.0003 & -2.978 & 0.003 & & $6.5 \%$ \\
& Gestational age & 0.178 & 0.031 & 5.657 & $<0.001$ & & $39.9 \%$ \\
& SGA & -0.278 & 0.162 & -1.711 & 0.088 & & $5.3 \%$ \\
& Sex & 0.471 & 0.085 & 5.518 & $<0.001$ & & $37.4 \%$ \\
& CLD & 0.091 & 0.106 & 0.854 & 0.394 & & $1.0 \%$ \\
& PN days & 0.002 & 0.002 & 0.777 & 0.438 & & $0.7 \%$ \\
& Site 2 & 0.113 & 0.100 & 1.132 & 0.258 & & $1.5 \%$ \\
& Site 3-4 & 0.155 & 0.133 & 1.163 & 0.246 & & $2.8 \%$ \\
\hline
\end{tabular}

CLD, chronic lung disease; FF, fortification; PN, parenteral nutrition; SGA, small for gestational age; SE, standard error. ${ }^{1}$ Box-Cox Transformation Linear Regression. ${ }^{2}$ Linear Regression using Yeo-Johnson transformation.

Table 5

Models for linear regression analyses for head circumference

\begin{tabular}{llcccccc}
\hline Parameter & Independent & Coefficient & SE & $\begin{array}{c}t \\
\text { Statistic }\end{array}$ & $p$-Value & $\begin{array}{c}\text { Adjusted } \\
\mathrm{R}^{2}\end{array}$ & $\begin{array}{c}\text { Feature } \\
\text { importance }\end{array}$ \\
\hline OFC Velocity $^{1}$ & Early FF & 0.030 & 0.013 & 2.319 & 0.021 & 0.198 & $3.1 \%$ \\
& Birth OFC & -0.030 & 0.004 & -7.864 & $<0.001$ & & $34.4 \%$ \\
& Gestational age & 0.024 & 0.004 & 5.890 & $<0.001$ & & $18.0 \%$ \\
& SGA & -0.051 & 0.018 & -2.831 & 0.005 & $3.1 \%$ \\
& Sex & 0.013 & 0.011 & 1.193 & 0.234 & & $0.9 \%$ \\
& CLD & 0.016 & 0.013 & 1.195 & 0.233 & & $1.3 \%$ \\
& PN days & -0.001 & 0.0003 & -4.866 & $<0.001$ & & $25.0 \%$ \\
& Site 2 & 0.035 & 0.013 & 2.729 & 0.007 & & $5.9 \%$ \\
OFC Change in & Site 3-4 & 0.054 & 0.017 & 3.229 & 0.001 & & $8.4 \%$ \\
z-score & Early FF & 0.273 & 0.137 & 1.998 & 0.046 & 0.381 & $0.8 \%$ \\
& Birth OFC & -0.494 & 0.040 & -12.489 & $<0.001$ & & $40.4 \%$ \\
& Gestational age & 0.484 & 0.043 & 11.378 & $<0.001$ & & $33.5 \%$ \\
& SGA & -0.445 & 0.187 & -2.382 & 0.018 & & $7.5 \%$ \\
& Sex & 0.615 & 0.113 & 5.434 & $<0.001$ & & $9.3 \%$ \\
& CLD & 0.252 & 0.141 & 1.789 & 0.074 & & $1.0 \%$ \\
& PN days & -0.007 & 0.003 & -2.445 & 0.015 & & $3.1 \%$ \\
& Site 2 & 0.063 & 0.133 & 0.476 & 0.634 & & $0.3 \%$ \\
& Site 3-4 & 0.458 & 0.174 & 2.628 & 0.009 & & $4.0 \%$ \\
\hline
\end{tabular}

CLD, chronic lung disease; FF, fortification; OFC, occipital frontal head circumference; PN, parenteral nutrition; SGA, small for gestational age; SE, standard error. ${ }^{1}$ Linear Regression using Yeo-Johnson transformation.

\section{Discussion}

This retrospective study found that fortification of human milk feedings with a human milk based fortifier at enteral feeding intakes $<60 \mathrm{~mL} / \mathrm{kg} /$ day compared to intakes of $>60 \mathrm{~mL} / \mathrm{kg} /$ day was associ- ated with greater growth velocities and less negative changes in z-scores for weight and head circumference in infants $<1250 \mathrm{~g}$ birth weight. Previous studies of infants receiving human milk fortified with human milk based fortifier found improved weight and length gain velocities associated with earlier 
fortification in a cohort study [5] as well as a retrospective study [4], although a randomized controlled study did not find a significant difference in growth velocities for infants fortified at lower versus higher enteral feeding volumes [1]. Studies of infants fortified at lower feeding volumes whose human milk was fortified with a bovine fortifier have not demonstrated improved growth in a retrospective study [7] and a randomized trial [8]. There was a lower incidence of elevated alkaline phosphatase levels in the retrospective study and cumulative protein intake was higher in the randomized trial for infants who received earlier fortification with the bovine fortifier. In the current study the impact of early fortification on growth outcomes, as indicated by the feature importance in Tables 4 and 5, was not large but it is a factor that can be affected by nutritional practices in the NICU. Weight gain velocities for infants in the current study are within the range (11.6- $15.6 \mathrm{~g} / \mathrm{kg} / \mathrm{day})$ of those reported in the literature for preterm infants supported with human milk feedings where weight gain velocity was calculated from birth to discharge using the exponential or the 2-point average methods [12-14]. Other studies in very preterm infants reporting greater weight gain velocities have either not given the method used to compute weight gain velocity [1], or used other methods which include using birth weight in the dominator [5], or using a lower weight in the denominator as well as calculating weight gain from the time of regaining birth weight to discharge [15].

There have been no adverse outcomes, including the incidence of NEC, associated with earlier fortification in any of the above studies or in the present study. The present study did find that earlier fortification was associated with a decreased incidence of CLD. A study of early nutrition support of extremely low birth weight infants has reported a positive effect of caloric intake on decreasing the incidence of CLD or death in critically ill infants [16]. Other studies have found an association of increasing protein intake in the first week of life with decreased CLD [17-18]. We do not have data to report protein intake during the first week of life. The use of continuous positive airway pressure (CPAP) and surfactant to decrease CLD has been shown to be due to decreasing days of mechanical ventilation [19]. A recent review identified mechanical ventilation and lower gestational age as risk factors for CLD [16], while others have emphasized the multifactorial pathophysiology as well as the importance of nutrition support including the use of human milk and vitamin A [20-22]. While there are factors that were not included in this retrospective study that may have impacted the incidence of CLD there was no difference between the late and early groups in the current study for days of mechanical ventilation, and vitamin A was not part of the nutrition support regimens at the study sites. In addition, days of mechanical ventilation were included in the logistic regression analysis for associations with CLD. Future studies designed to evaluate prevention strategies for CLD should be enhanced by including nutritional data as variables in the study and nutrition support protocols in the study design.

There are limitations to this study. It is retrospective and, therefore, significant findings are associations and do not prove causation. There were some differences in nutrition support practices among sites, including the initial dose of AA begun on day of life one, but the regression analyses included site as a predictor, therefore, the association of fortification group with specific outcomes was controlled for site. According to a recent Cochrane Review [23] the data showed that early high versus low AA intake effects growth is "very low quality" and a recent randomized controlled trial published since the Cochrane Review found no positive effect of early high versus low dose AA intake on the growth of very low birth weight preterm infants [24]. There may be other predictors that were not included in the statistical analyses that could affect growth such as the intakes of mother's own milk versus donor milk, as well as, the actual nutrient composition of the human milk received by infants in the study.

In summary, this study provides further data to support the practice of fortifying the human milk feedings of infants with $\leq 1250 \mathrm{~g}$ birth weight at a lower feeding volume than has been a standard feeding practice in the past. Early fortification appears to be safe and may enhance growth in the NICU, as well as, improve some short term outcomes, such as CLD.

\section{Disclosure statements}

Martin L. Lee, PhD and Vera L. Chan, BA are employees of Prolacta Bioscience (City of Industry, CA). Evelyn D. Rider, MD is a consultant for Prolacta Bioscience.

\section{References}

[1] Sullivan S, Schanler RJ, Kim JH, Patel AL, Trawoeger R, Kiechl-Kohlendorfer U et al. An exclusively human milkbased diet is associated with a lower rate of necrotizing 
enterocolitis than a diet of human milk and bovine milkbased products. J Pediatr. 2010;156:562-567.

[2] Cristofalo EA, Schanler RJ, Blanco CL, Sullivan S, Trawoeger R, Kiechl-Kohlendorfer U et al. Randomized trial of exclusive human milk versus preterm formula diets in extremely premature infants. J Pediatr. 2013;163:15921595.

[3] Herman K, Carroll K. An exclusive human milk diet reduces necrotizing enterocolitis. Breastfeed Med. 2014;9:184-190.

[4] Huston RK, Markel AM, McCulley EA, Gardiner SK, Sweeney SL. Improving growth for infants $<1250$ grams birth weight receiving human milk diets. Nutr Clin Pract. 2018;33:671-678.

[5] Hair AB, Hawthorne KM, Chetta KE, Abrams SA. Human milk feeding supports adequate growth in infants $<1250$ grams birth weight. BMC Res Notes. 2013;6:459-466.

[6] Hair AB, Blanco CL, Moreira AG, Hawthorne KM, Lee ML, Rechtman DJ, et al. Randomized trial of human milk cream as a supplement to standard fortification of an exclusive human milk-based diet in infants 750-1250g birth weight. J Pediatr. 2014; 165:915-920.

[7] Tillman S, Brandon DH, Silva SG. Evaluation of human milk fortification from the time of the first feeding: effects on infants less than 31 weeks gestational age. J Perinatol. 2012;32:525-531.

[8] Shaw SD, Dereddy N, Jones TL, Dhanireddy R, Talati A. Early versus delayed human milk fortification in very low birth weight infants-a randomized controlled trial. J Pediatr. 2016;174:126-131.

[9] Fenton TR, Kim JH. A systematic review and meta-analysis to revise the Fenton growth chart for preterm infants. BMC Pediatrics. 2013;13:59-71.

[10] Walsh MC, Kliegman RM. Necrotizing enterocolitis: treatment based on staging criteria. Pediatr Clin North Am. 1986;33(1):179-201.

[11] Patel AL, Engstrom JL, Meier PP, Kimura RE. Accuracy of methods for calculating postnatal growth velocity for extremely low birth weight infants. Pediatrics. 2005;116:1466-1473.

[12] Assad M, Elliott MJ, Abraham JH. Decreased cost and improved feeding tolerance in VLBW infants fed an exclusive human milk diet. J Perinatol. 2016;36:216-220.

[13] Colacci M, Murthy k, DeRegnier RAO, Khan JY, Robinson DT. Growth and development in extremely low birth weight infants after introduction of exclusive human milk feedings. Am J Perinatol. 2017;34:130-137.

[14] Eibensteiner F, Auer-Hackenberg L, Jilma B, Thanhaeuser M, Wald M, Haiden N. Growth, feeding tolerance and metabolism in extreme preterm infants under an exclusive human milk diet. Nutrients 2019;26;11(7).

[15] Ehrenkranz RA, Dusick AM, Vohr BR, Wright LL, Wrage LA, Poole WK. Growth in the neonatal intensive care unit influences neurodevelopmental and growth outcomes of extremely low birth weight infants. Pediatrics. 2006;117(4):1253-1261.

[16] Ehrenkranz RA, Das A, Wrage LA, Poindexter BB, Higgins $\mathrm{RD}$, Stoll BJ et al. Early nutrition mediates the influence of severity of illness on extremely LBW infants. Pediatr Res. 2011;69(6):522-529.

[17] Alshaikh BN, Buddhavarapu S, Sauve R, Akierman A, Soraisham A. Impact of early caloric and protein intake on the risk for bronchopulmonary dysplasia in extremely preterm infants. Pediatric Academic Societies Annual Conference, May 3-6, 2014, Vancouver, Canada; E-PAS2014: 2930.448.

[18] Yang J, Chang SSY, Poon WB. Relationship between amino acid and energy intake and long-term growth and neurodevelopmental outcomes in very low birth weight infants. JPEN J Parenter Enteral Nutr. 2016;40(6):820-826.

[19] Fischer HS, Buhrer C. Avoiding endotracheal ventilation to prevent bronchopulmonary dysplasia: a meta-analysis. Pediatrics. 2013;132(5):e1351-e1360.

[20] Nayeri UA, Buhimschi CS, Zhao G, Buhimschi IA, Bhandari V. Components of the antepartum, intrapartum, and postpartum esposome impact on distinct short-term adverse neonatal outcomes of premature infants: A prospective cohort study. PLoS One. 2018. doi.org/10.1371/journal. pone.0207298.

[21] McEvoy CT, Jain L, Schmidt B, Abman, S, Bancalari E, Aschner JL. Bronchopulmonary dysplasia: NHLBI workshop on the primary prevention of chronic lung disease. AnnalsATS. 2014;11(Suppl 3):S146-S153.

[22] Aschner JL, Bancalari EH, McEvoy CT. Can we prevent bronchopulmonary dysplasia. J Pediatr. 2017;189:26-30.

[23] Osborn DA, Schinder T, Jones LJ, Sinn JK, Bolisetty S. Higher versus lower amino acid intake in parenteral nutrition for newborn infants. Cochrane Database Syst Rev. 2018;3: CD005949

[24] Balakrishnan M, Jennings A, Przystac L, Phornphutkul C, Tucker R, Vohr B, et al. Growth and neurodevelopmental outcomes of early high-dose parenteral amino acid intake in very low birth weight infants: a randomized controlled trial. JPEN J Parenter Enteral Nutr. 2018;42(3):597-606. 